Article

\title{
Synthesis and Properties of Novel Calcia-Stabilized Zirconia (Ca-SZ) with Nano Calcium Oxide Derived from Cockle Shells and Commercial Source for Dental Application
}

\author{
Abbas Ibrahim Hussein ${ }^{1,2}$, Ahmad Nazeer Che Mat ${ }^{3}$, Nur Ain Adila Abd Wahab ${ }^{3}$, \\ Ismail Ab. Rahman ${ }^{3}$, Adam Husein ${ }^{1,4}$ and Zuryati Ab-Ghani 1,4,*(D) \\ 1 Prosthodontic Unit, School of Dental Sciences, Health Campus, Universiti Sains Malaysia, \\ Kubang Kerian 16150, Kelantan, Malaysia; abbass_69@yahoo.com (A.I.H.); adamkck@usm.my (A.H.) \\ 2 Department of Prosthodontic Dentistry, College of Dentistry, University of Anbar, Ramadi 31001, Iraq \\ 3 Department of Biomaterials, School of Dental Sciences, Health Campus, Universiti Sains Malaysia, \\ Kubang Kerian 16150, Kelantan, Malaysia; hmd_naz@yahoo.com (A.N.C.M.); \\ adeelawahab95@gmail.com (N.A.A.A.W.); arismail@usm.my (I.A.R.) \\ 4 Hospital Universiti Sains Malaysia, Kubang Kerian 16150, Kelantan, Malaysia \\ * Correspondence: zuryati@usm.my
}

Received: 26 July 2020; Accepted: 18 August 2020; Published: 20 August 2020

Featured Application: The Ca-SZ fabricated in the current study may be used as framework for construction of dental crown and bridgework.

\begin{abstract}
Various oxides are used to stabilize zirconium oxide $\left(\mathrm{ZrO}_{2}\right)$, but their superior hardness causes wear of the machining tool. Calcia-doped zirconia has been studied but reports on properties suitable for dental application are lacking. Therefore, this study aimed to fabricate and characterize zirconia stabilized by calcium oxide $(\mathrm{CaO})$ derived from cockle shells and compare it with zirconia stabilized by commercial $\mathrm{CaO}$, sintered at different temperatures. In this study, 176 pressed pellets of zirconia mixed with $\mathrm{CaO}$ either derived from cockle shells or commercial $\mathrm{CaO}$ were sintered between 1200 and $1500{ }^{\circ} \mathrm{C}$ to produce calcia-doped zirconia. Characterizations were made with SEM and XRD. Specimens were subjected to density, compressive and flexural strength, and Vickers hardness testing. Data were analyzed using the independent $t$-test and one-way ANOVA. XRD revealed the zirconia was stabilized into tetragonal and cubic phases (Ca-SZ). Ca-SZ cockle shells (CS) and Ca-SZ commercial (CC) have average particle sizes of $267 \mathrm{~nm}$ and $272 \mathrm{~nm}$, respectively, with similar surface roughness. At $1400{ }^{\circ} \mathrm{C}$ sintering temperature, flexural strengths were 1165 and $1152 \mathrm{MPa}$, compressive strengths were 4914 and $4913 \mathrm{MPa}$, and Vickers hardness were 977 and $960 \mathrm{MPa}$ for Ca-SZ(CS) and Ca-SZ(CC), respectively. Both Ca-SZ materials showed no significant difference in most properties $(p<0.05)$ when sintered at different temperatures. The fully sintered Ca-SZ is less hard compared to the ceria-stabilized tetragonal zirconia polycrystal (Ce-TZP) available on the market. Thus, Ca-SZ may be used as an alternative to the current zirconia available on the market for dental application.
\end{abstract}

Keywords: sintering; zirconia; calcium oxide; cockle shell; Ca-SZ; flexural strength

\section{Introduction}

Zirconia-based ceramics have been used as dental implants [1] in addition to framework underneath the brittle veneering porcelain in the fabrication of fixed dental prostheses, such as 
crowns and bridges [2]. As the aesthetic properties of zirconia-based ceramics improve, they have also been used to construct the whole crown and bridge works in combination with computer-aided design/computer-aided manufacturing (CAD/CAM) [3].

Pure zirconia has three polymorphic forms at atmospheric pressure: monoclinic from room temperature until $1170{ }^{\circ} \mathrm{C}$, tetragonal $\left(1170-2370{ }^{\circ} \mathrm{C}\right)$ and cubic $\left(2370-2680{ }^{\circ} \mathrm{C}\right)$ [4]. However, pure zirconia encounters a setback whereby upon cooling of the polymorphs, large volume change occurs, which would result in the cracking of the brittle products. Incorporation of a small percentage of cubic oxide stabilizers such as yttria $\left(\mathrm{Y}_{2} \mathrm{O}_{3}\right)$, ceria $\left(\mathrm{CeO}_{2}\right)$, magnesia $(\mathrm{MgO})$, and calcia $(\mathrm{CaO})$ to zirconia can delay the creation of the transformation phase $[5,6]$. Subsequently, the zirconia crystals in their tetragonal or cubic shape at room temperature remain stable. Zirconia-containing ceramic systems currently used in dentistry are yttrium cation-doped tetragonal zirconium polycrystals (3Y-TZP), magnesium cation-doped partially stabilized zirconium (Mg-PSZ), zirconium-toughened alumina (ZTA) and ceria-stabilized zirconia-alumia (CeTZP/A) [3,7,8].

Yttrium partially stabilized tetragonal zirconia polycrystalline (Y-TZP) bridge framework with a high fracture toughness, from 5 to $10 \mathrm{MPa} \mathrm{m}^{1 / 2}$, and a flexural strength of $900-1400 \mathrm{MPa}[9,10]$ can be fabricated by milling either fully sintered blocks or partially sintered blocks/green blocks using computer-aided design/computer-aided manufacture (CAD/CAM) procedures [11]. However, yttrium-stabilized zirconia has the disadvantage of inferior machining associated with wear of the tool due to its superior hardness. Partially sintered Y-TZP produces extensive sintering shrinkage during the post-sintering process, which might affect the final fit of the zirconia framework [12]. Y-TZP also suffers from low-temperature aging degradation (LTAD) caused by phase transformation [13]. Ce-TZP/A is the toughest dental ceramic material available, with a fracture toughness of $19 \mathrm{MPa} \mathrm{m}^{1 / 2}$, and a flexural strength of $1400 \mathrm{MPa}$ [8]. Although alumina and ceria, as stabilizing oxides, reduce the susceptibility of zirconia to LTAD [14], they can cause wear of the milling machine if milled fully sintered, due to their superior hardness. Therefore, other partially and fully stabilized zirconia, for example Ca- PSZ, may be used as suitable replacement materials for dental application.

Studies have been conducted to produce calcia-doped zirconia in biomedical application such as for hip and knee replacement. Nath in 2008 sintered Ca-PSZ for a hip replacement implant. The material exhibits modest fracture toughness $\left(6 \mathrm{MPa}{ }^{1 / 2}\right)$. This property is better than commercial grade alumina, but lower than Y-TZP and Ce-TZP/A [15]. Therefore, Ca-PSZ is a possible material that has a better combination of mechanical properties than other commercially available bioceramics, as it can give optimum strength but at the same time does not wear the CAD/CAM milling machine.

Drazin and Castro in 2016 reported that calcia-doped zirconia exhibits all the polymorphism seen in the yttria-doped zirconia ceramics, but can be produced at lowered costs and in greater abundance due to the accessibility of calcium precursors in comparison to yttrium [16]. In most cases, the particles sizes of stabilizers are not clearly specified. Moreover, the reports have mostly focused on the synthesis of the calcia-doped zirconia, but the use of nano-CaO derived from cockle shells to stabilize zirconia for dental application has not been reported.

In our previous study, spherical nano-CaO was successfully extracted from cockle shells [17]. Cockle shells are a natural source of nano- $\mathrm{CaO}$ and are readily available as waste. $\mathrm{CaO}$ is non-toxic and biocompatible in many applications and is one of the compositions of hydroxyapatite in human bone. In the current study, nano-CaO derived from cockle shells was used to stabilize zirconia. It is therefore important to investigate whether the incorporation of nano-CaO derived from cockle shells into zirconia will produce a better microstructure of $\mathrm{CaO}$-stabilized zirconia with good material properties, as often obtained by the commercial $\mathrm{CaO}$. One of the major aims of the present work is to address this issue. The other issue to be addressed is whether the nano-CaO derived from cockle shells stabilized zirconia is less hard than alumina- and yttria-stabilized zirconia.

If the nano-CaO stabilized zirconia derived from cockle shells and from commercial source are comparable, then it may be used as a stabilizer in the fabrication of zirconia for dental application. The cockle shells are readily available as waste. Therefore, using nano-CaO from cockle shells not only 
will have the benefit of waste removal (recycling), but at the same time produce added value to the cockle shell waste.

Therefore, the purpose of this study was to synthesize and investigate the effect of different sintering temperatures on the physical and mechanical properties of novel calcia-stabilized zirconia (Ca-SZ) with the $\mathrm{CaO}$ derived from cockle shells and compare it to the $\mathrm{Ca}$-SZ stabilized by commercial $\mathrm{CaO}$.

\section{Materials and Methods}

\subsection{Materials}

Commercially available zirconium oxide $\left(\mathrm{ZrO}_{2}\right)$ nanopowder $(<40 \mathrm{~nm})$ and commercial $\mathrm{CaO}$ nanopowder $(<160 \mathrm{~nm}) \mathrm{CaO}$ (CC) were purchased from Sigma, Ronkonkoma, NY, USA. Calcium oxide nanopowder $(22-70 \mathrm{~nm})$ derived from cockle shells $\mathrm{CaO}$ (CS) was prepared according to protocol as described in a previous study [17].

\subsection{Extraction of Calcium Oxide Cockle Shells}

Local cockle shells were collected from a local beach, Pantai Bachok. The cockle shells were washed, pulverized and sieved to form a uniform sized cockle shell powder of $63 \mu \mathrm{m}$. The cockle shell powder was dissolved in hydrochloric acid to produce calcium chloride $\left(\mathrm{CaCl}_{2}\right)$, which was then titrated with ethanol and potassium carbonate to form insoluble calcium carbonate $\left(\mathrm{CaCO}_{3}\right)$. This was followed by calcination of $\mathrm{CaCO}_{3}$ at $750{ }^{\circ} \mathrm{C}$ for $30 \mathrm{~min}$ to produce spherical, nano-CaO powder, which was used in the current study.

\subsection{Fabrication of $\mathrm{CaO}$ Stabilized Zirconia Pellet}

To prepare the zirconia specimen pellet, $9.2 \mathrm{~g}$ of zirconium oxide (92\%) was mixed with $0.8 \mathrm{~g}$ of calcium oxide $(8 \%)$, either $\mathrm{CaO}(\mathrm{CS})$ or $\mathrm{CaO}(\mathrm{CC})(8 \%)$. The mixed powder was placed in a plastic bottle containing ceramic balls, which was then placed on an electric mixer for $30 \mathrm{~min}$ to allow for proper mixing. Then, the inner surface of a stainless steel mold with the dimension of $32 \mathrm{~mm}$ in diameter and $6 \mathrm{~mm}$ in height was isolated with silicone wax-based separating medium. The mixed powder was placed in the stainless steel mold, and then pressed using a hydraulic press (Atlas ${ }^{\mathrm{TM}}$ Manual $15 \mathrm{~T}$ and $25 \mathrm{~T}$ Hydraulic Press, Specac, Kent, Orpington, UK) under 5 tons (60 Mpa) pressure. A total of 176 pressed zirconia specimen pellets were then divided into four groups according to the different sintering temperatures. Each group was sintered in a furnace (Linn High Therm Furnace VMK-1800) for two hours at four different temperatures $\left(1200,1300,1400\right.$, and $\left.1500^{\circ} \mathrm{C}\right)$ to produce pellet blanks of calcia-stabilized zirconia (Ca-SZ) with either $\mathrm{CaO}$ derived from cockle shells (CS) or commercial CaO (CC), which from here on will be called Ca-SZ(CS) and Ca-SZ(CC), respectively. An example of the sintered zirconia pellet blank is shown in Figure 1.

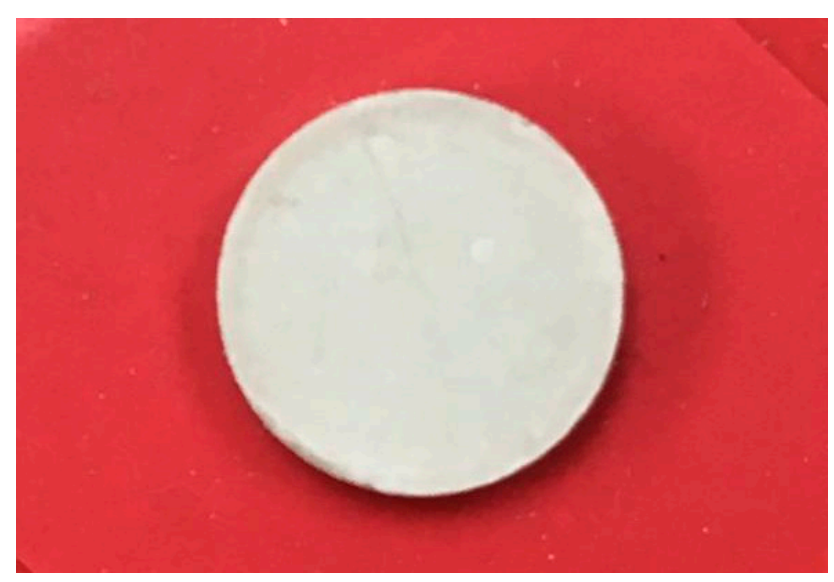

Figure 1. Sintered calcium oxide $(\mathrm{CaO})$-stabilized zirconia pellet blank. 


\subsection{Physical and Mechanical Tests of $\mathrm{Ca}-\mathrm{SZ}(\mathrm{CS})$ and $\mathrm{Ca}-\mathrm{SZ}(\mathrm{CC})$ Sintered at Different Temperatures}

Eight specimens from both Ca-SZ(CS) and Ca-SZ(CC) groups sintered at different temperatures were analyzed with an X-ray diffractometer (XRD) (Shimadzu XRD-6000 powder diffractometer) using $\mathrm{Cu} \mathrm{K} \alpha$ radiation $(\lambda=1.5406 \AA, 40 \mathrm{kV}$ at $160 \mathrm{~mA})$ at a scan rate of $0.05^{\circ} 2 \theta \mathrm{s}^{-1}$.

Another eight specimens, from each group sintered at four different temperatures, were analyzed using a scanning electron microscope (SEM) (LEICA EM SCD005, Bannockburn, IL, USA). Specimens were then polished using an electric polishing machine (EXAKT 400CS, AW110, Oklahoma City, OK, USA) with $300 \mathrm{~mm}$ Schleifscheiben sandpaper discs (Hermes Schleifmittel GmbH \& Co. KG, Hamburg, Germany) at different grit sizes (P500, P800, P1000 and P1200) for $15 \mathrm{~min}$ for each grit, at $5000 \mathrm{rpm}$. Water was used to prevent the overheating of the samples. The sandpaper was changed for every sample. After that, the polished specimens were then re-analyzed using the SEM machine.

Forty specimens from both groups, sintered at four different temperatures $(n=5)$, were weighed on a precision balance using Mettler Toledo DA110 toploading electrical balance (Tokyo, Japan), before and after immersion in double distilled water (DDW), for actual and suspended weights, respectively. Archimedes' principle was used to measure the density of sintered specimens. The following formula was used to calculate the density [18].

$$
\rho=\frac{\text { actualweight }}{(\text { actual }- \text { suspended })} \times \rho_{\mathrm{w}}
$$

where, $\rho$ is the calculated density $\left(\mathrm{g} / \mathrm{cm}^{3}\right)$ and $\rho_{\mathrm{w}}$ is the density of the water $\left(\mathrm{g} / \mathrm{cm}^{3}\right)$.

Forty specimens with dimensions of $25 \mathrm{~mm} \times 2 \mathrm{~mm} \times 2 \mathrm{~mm}$ were measured with vernier calipers and cut using a micro motor handpiece driven at 30,000 rpm for a flexural strength test $(n=5)$. Another 40 specimens with dimensions of $6 \mathrm{~mm}$ height $\times 4 \mathrm{~mm}$ diameter (International Standards Organization (ISO) no. 9917 (2000)) were prepared for a compressive strength test $(n=5)$. Another 40 specimens measuring $30 \mathrm{~mm} \times 10 \mathrm{~mm} \times 2.5 \mathrm{~mm}$ (International Standards Organization (ISO) Specification no. 1567) were prepared for the Vickers hardness test $(n=5)$. The cut specimens were polished using the same protocol mentioned above. The flexural strength and compressive strength of the specimens were tested using the universal testing machine (Shimadzu, Model: AGX plus $20 \mathrm{kN}$, Kyoto, Japan) at the crosshead speed of $0.75 \mathrm{~mm} / \mathrm{min}$. The formula used for calculating the flexural strength and compressive strength was: Flexural strength $=3 \mathrm{PL} / 2 \mathrm{bd}^{2}$ where, $\mathrm{P}$ is the maximum force applied, $\mathrm{L}$ is the span length, $\mathrm{b}$ is the width, $\mathrm{d}$ is the thickness; Compressive strength $=4 \mathrm{P} / \pi \mathrm{d}^{2}$ where P stands for maximum force applied and $\mathrm{d}$ is the specimen diameter. For measuring hardness, a load of $1000 \mathrm{~g}=9.81$ newtons earth was placed on the top surface of the polished surface of the specimens by the Vickers hardness indenter.

Statistical Analyses

The one-way ANOVA test was used to analyze the means of flexural, compressive, Vickers hardness and density of the materials sintered at different temperatures, with $p<0.05$ considered as significant. After checking the equal variance, the post-hoc Tukey test was used for multiple comparisons between the groups. The independent $t$ test was used to analyze the mechanical and physical strengths between Ca-SZ(CS) and Ca-SZ(CC), with $p<0.05$ considered significant.

\section{Results}

\subsection{XRD Analyses}

The phase identification of the prepared Ca-SZ using XRD are shown in Figure 2A,B. The diffraction patterns of cubic $\mathrm{ZrO}_{2}$ were obtained at $2 \theta=28^{\circ}, 41^{\circ}$ and $47^{\circ}$, corresponding to the Inorganic Crystal Structure Database (ICDS) no. 98-007-2021. Moreover, the tetragonal $\mathrm{ZrO}_{2}$ was obtained at $2 \theta=30^{\circ}$, $31.5^{\circ}, 34^{\circ}, 50^{\circ}, 60^{\circ}$ and $62.7^{\circ}$, corresponding to ICDS no. 98-010-8644. The zirconia was successfully stabilized with nano-CaO derived from cockle shells and from commercial source into tetragonal and 
cubic phases. The peaks at an angle $2 \theta=49^{\circ}$ and $54^{\circ}$ are assigned to the $\mathrm{CaO}$ structure corresponding to ICDS no. 01-073-5492. The same patterns were obtained for all samples at different sintering temperatures, which diverged only in the peak intensities. The increase in sintering temperature results in increasing the intensity of the cubic phase.

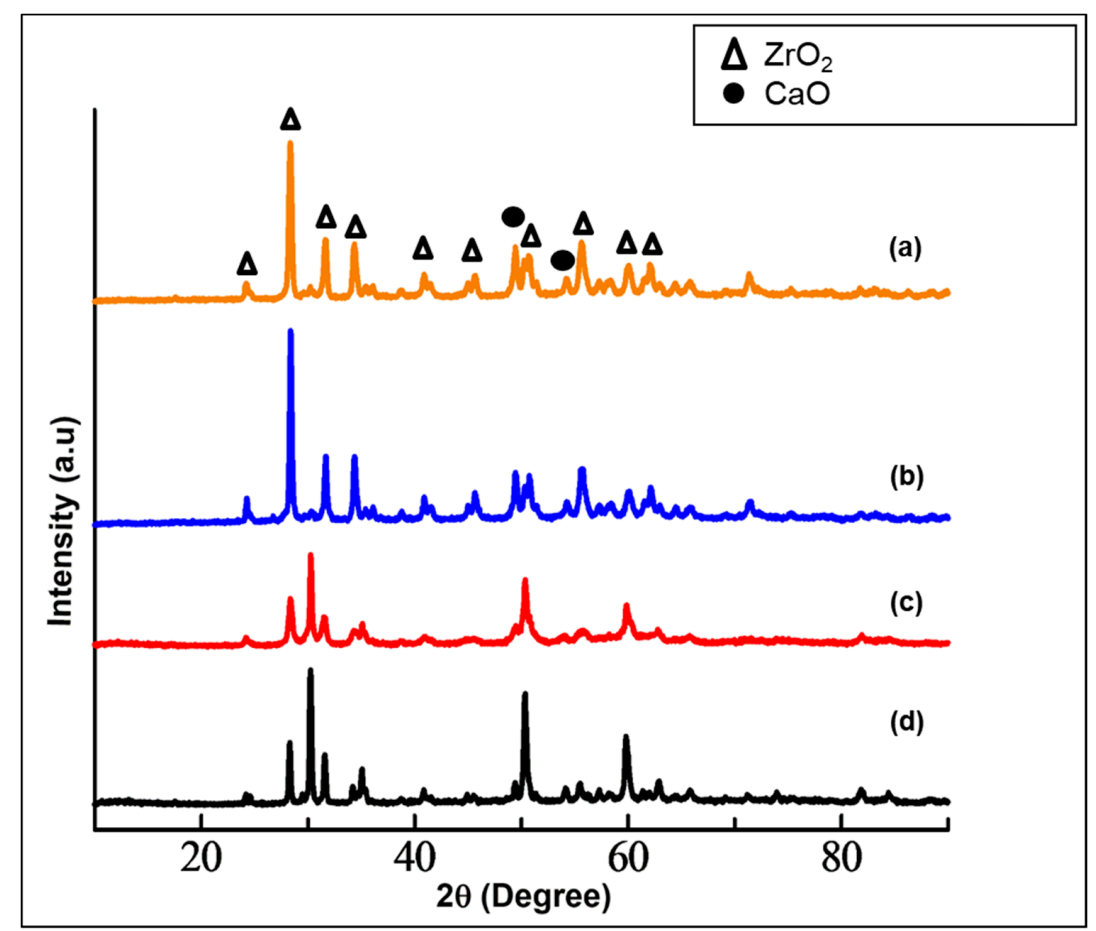

(A)

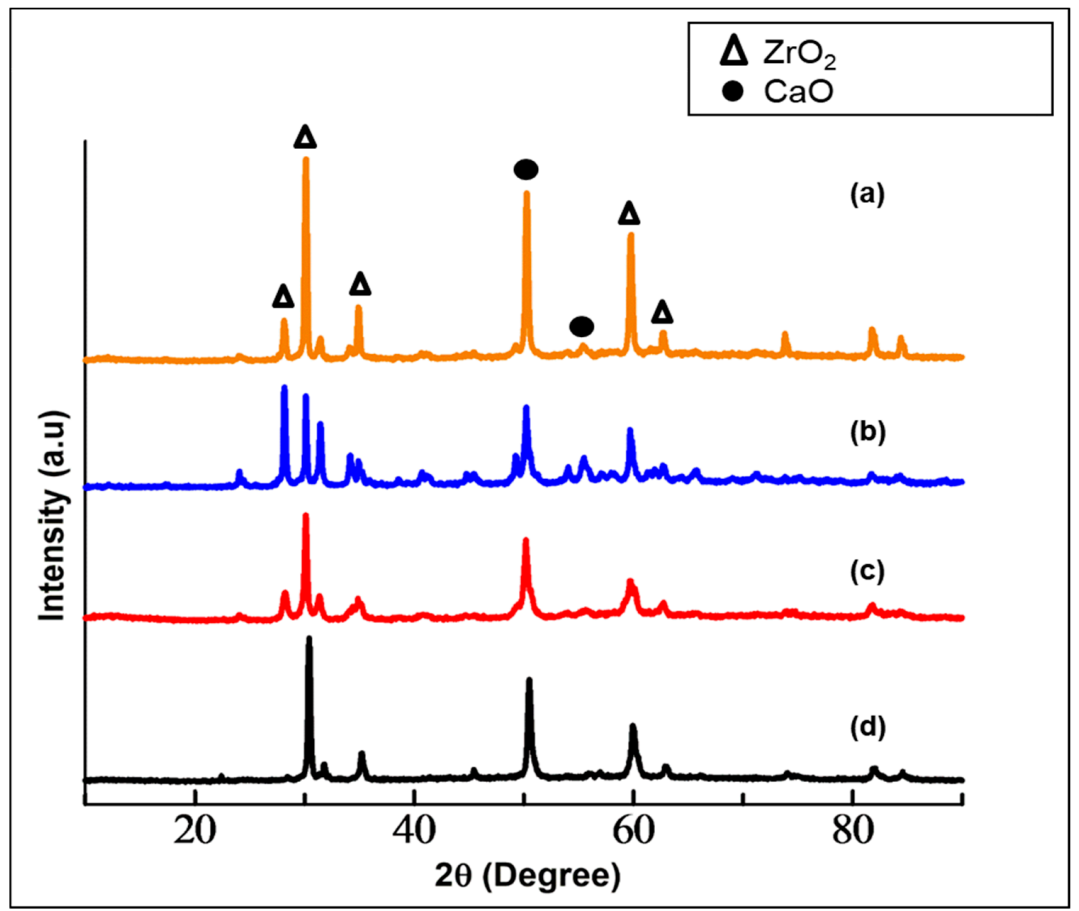

(B)

Figure 2. (A) XRD patterns of calcia-stabilized zirconia with CaO derived from cockle shells (Ca-SZ(CS)) sintered for $2 \mathrm{~h}$ at (a) $1500{ }^{\circ} \mathrm{C}$; (b) $1400{ }^{\circ} \mathrm{C}$; (c) $1300{ }^{\circ} \mathrm{C}$; (d) $1200{ }^{\circ} \mathrm{C}$. (B) XRD patterns of calcia-stabilized zirconia with $\mathrm{CaO}$ derived from commercial $\mathrm{CaO}(\mathrm{Ca}-\mathrm{SZ}(\mathrm{CC}))$ sintered for $2 \mathrm{~h}$ at (a) $1500^{\circ} \mathrm{C}$; (b) $1400^{\circ} \mathrm{C}$; (b) $1300{ }^{\circ} \mathrm{C}$; (d) $1200{ }^{\circ} \mathrm{C}$. 


\subsection{SEM Analyses}

The SEM analyses indicated that the average particle size of Ca-SZ derived from cockle shells and commercial nano-CaO are $64 \mathrm{~nm}$ and $110 \mathrm{~nm}$, respectively, before sintering (Figure 3). The SEM also show the uniform and even distribution of the particles.
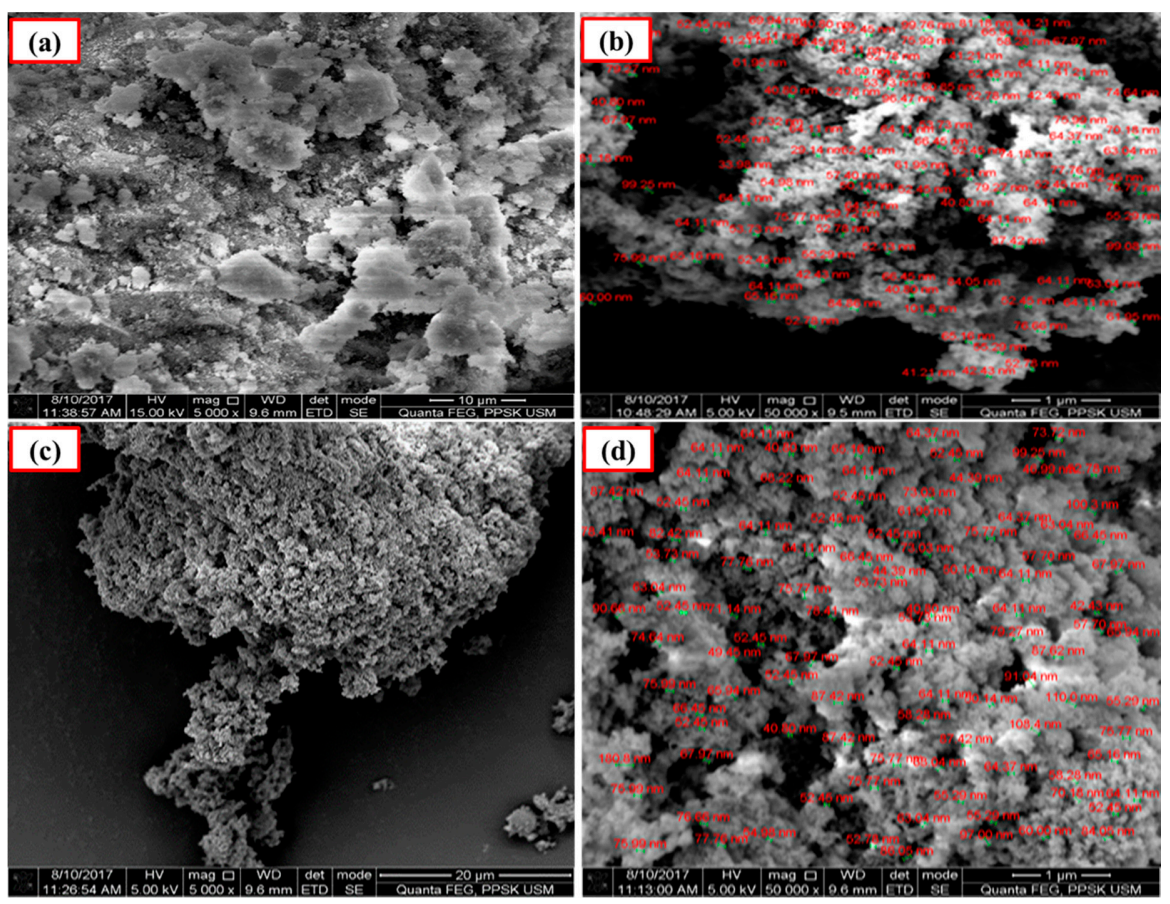

Figure 3. SEM images of calcia-stabilized zirconia (Ca-SZ) pellets before sintering. (a,b): CaO derived from cockle shells; (c,d): commercial nano-CaO.

Figures 4 and 5 show the images of unpolished Ca-SZ(CS) and Ca-SZ(CC) pellets, respectively, when sintered for two hours at 1200, 1300, 1400 and $1500{ }^{\circ} \mathrm{C}$. Unpolished Ca-SZ pellets from both groups show irregular and rough surfaces at all four different sintering temperatures, with the roughest surface at $1200^{\circ} \mathrm{C}$.
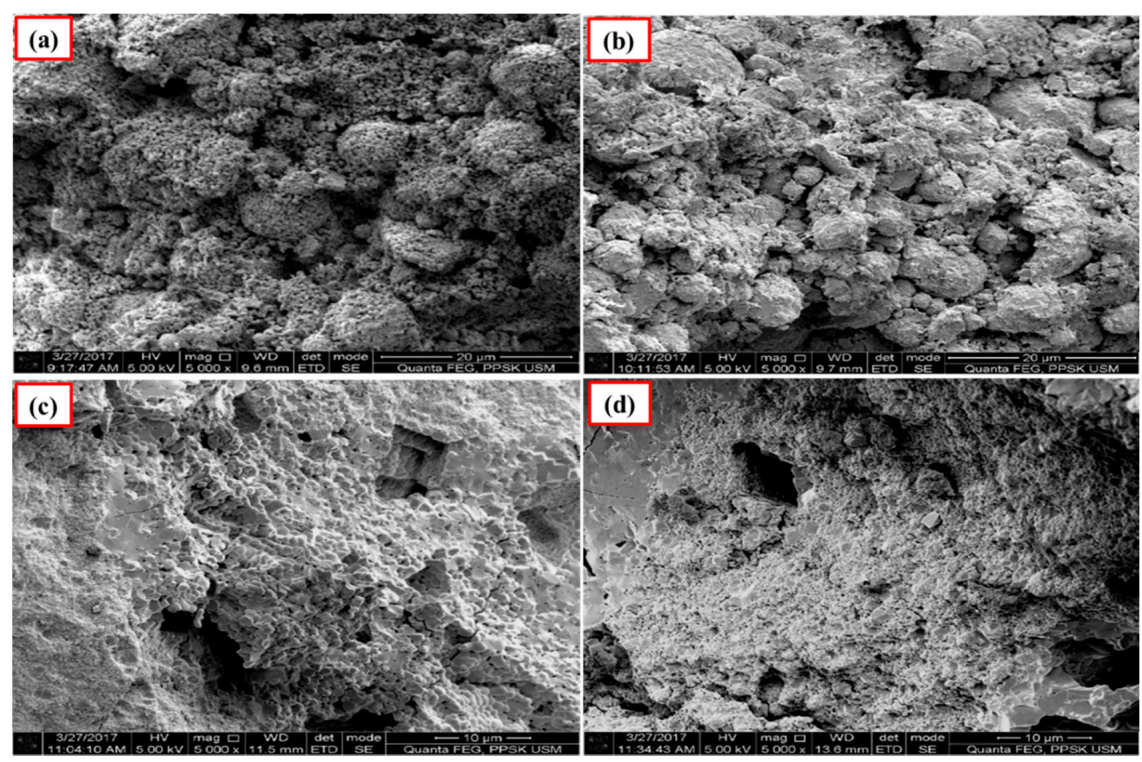

Figure 4. SEM images of the unpolished Ca-SZ(CS) sintered for $2 \mathrm{~h}$ at (a) $1200{ }^{\circ} \mathrm{C}$; (b) $1300{ }^{\circ} \mathrm{C}$; (c) $1400{ }^{\circ} \mathrm{C}$ and (d) $1500{ }^{\circ} \mathrm{C}$. 

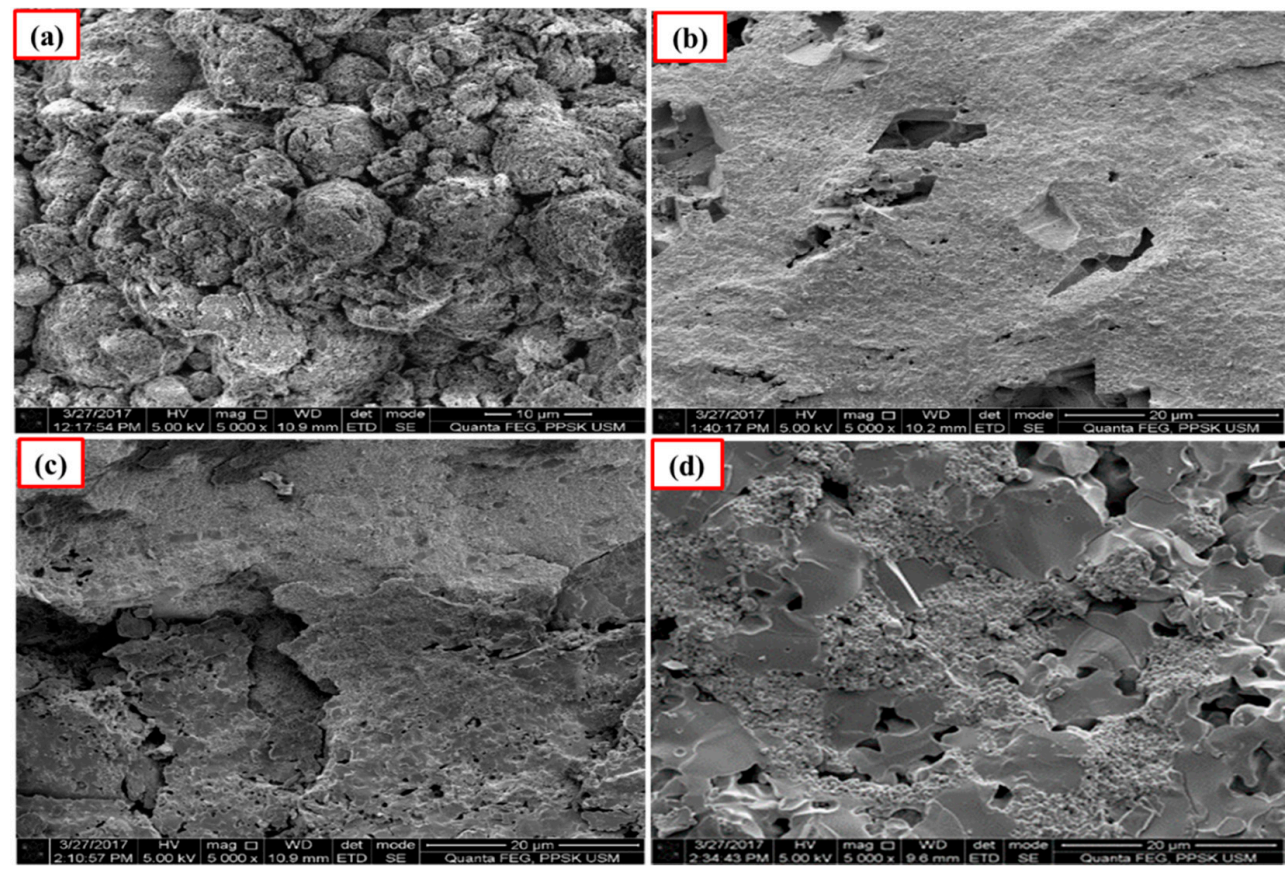

Figure 5. SEM images of the unpolished Ca-SZ(CC) sintered for $2 \mathrm{~h}$ at (a) $1200{ }^{\circ} \mathrm{C}$; (b) $1300{ }^{\circ} \mathrm{C}$; (c) $1400{ }^{\circ} \mathrm{C}$ and (d) $1500{ }^{\circ} \mathrm{C}$.

The polished surface of Ca-SZ(CS) pellets (Figure 6), show voids and spaces when sintered at $1200{ }^{\circ} \mathrm{C}$ and $1300{ }^{\circ} \mathrm{C}$, similar to the polished surface of Ca-SZ(CC) when sintered at $1200{ }^{\circ} \mathrm{C}$ (Figure 7). The polished surface of Ca-SZ(CC) was relatively smooth when sintered at $1300{ }^{\circ} \mathrm{C}, 1400{ }^{\circ} \mathrm{C}$ and $1500^{\circ} \mathrm{C}$. Ca-SZ(CS) sintered at $1400^{\circ} \mathrm{C}$ showed comparatively the glossiest appearance with minimum surface crack in addition to the smooth texture. Meanwhile, the particle sizes of Ca-SZ derived from both sources post-sintering showed no significant difference, with the value of $267 \mathrm{~nm}$ and $272 \mathrm{~nm}$ for Ca-SZ(CS) and Ca-SZ(CC), respectively.
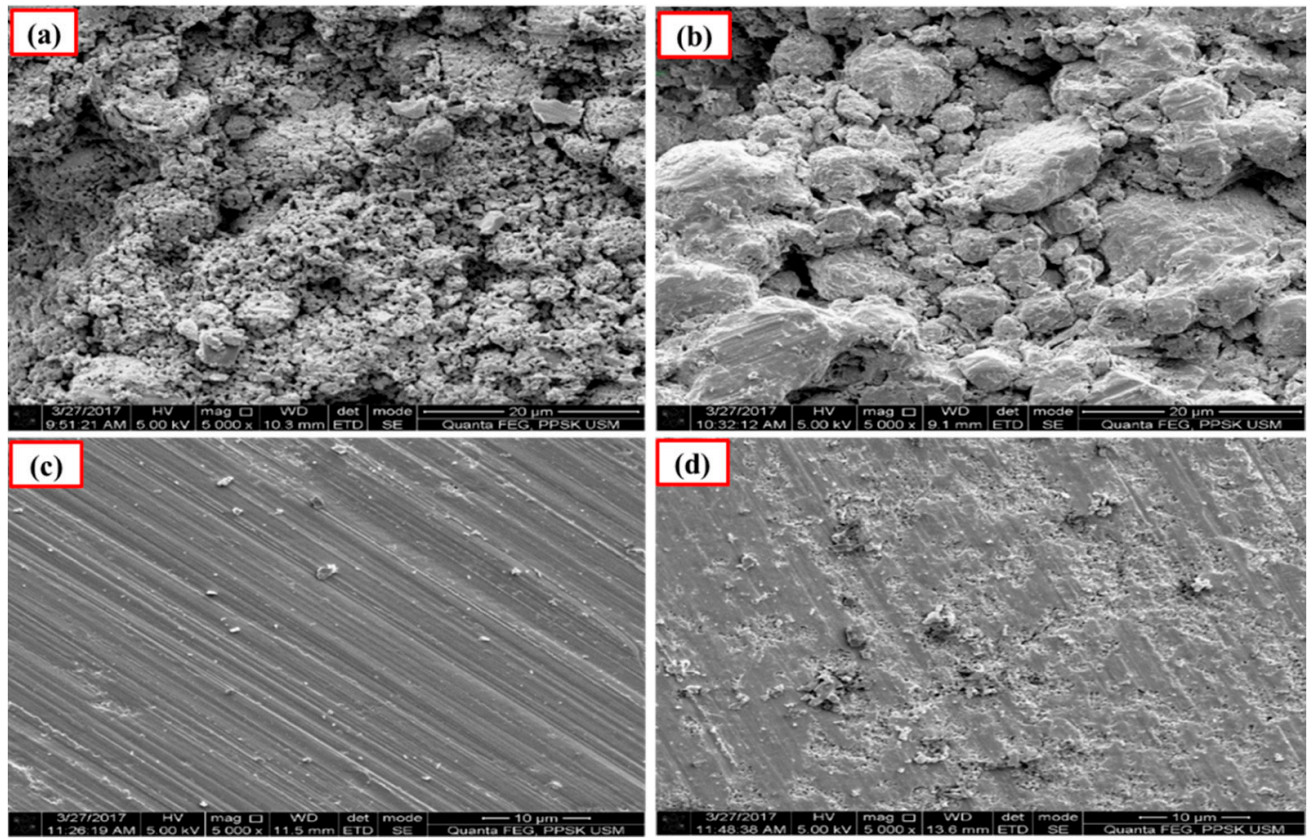

Figure 6. SEM images of polished Ca-SZ(CS) sintered for $2 \mathrm{~h}$ at (a) $1200{ }^{\circ} \mathrm{C}$; (b) $1300{ }^{\circ} \mathrm{C}$; (c) $1400^{\circ} \mathrm{C}$ and (d) $1500^{\circ} \mathrm{C}$. 

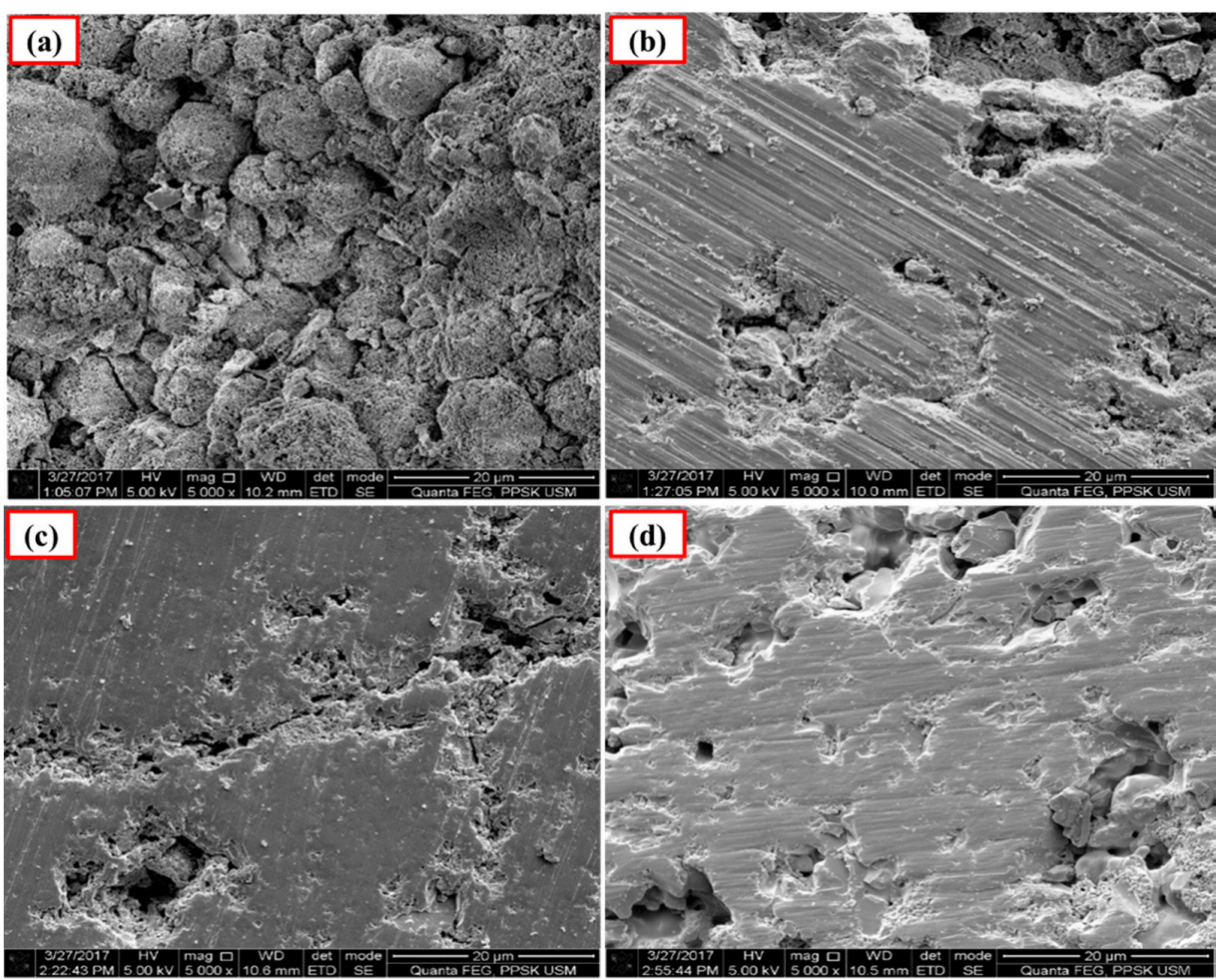

Figure 7. SEM images of the polished Ca-SZ(CC) sintered for $2 \mathrm{~h}$ at (a) $1200{ }^{\circ} \mathrm{C} ;$ (b) $1300{ }^{\circ} \mathrm{C} ;$ (c) $1400^{\circ} \mathrm{C}$ and (d) $1500{ }^{\circ} \mathrm{C}$.

\subsection{Density}

The densities of the prepared Ca-SZ(CS) and Ca-SZ(CC) are shown in Figure 8. As the sintering temperature increased, the density of the Ca-SZ increased up to $1400^{\circ} \mathrm{C}$ and levelled off as the sintering temperature further increased to $1500{ }^{\circ} \mathrm{C}$. The independent $t$-test showed that the mean density of $\mathrm{Ca}-\mathrm{SZ}(\mathrm{CS})$ was not significantly different from Ca-SZ(CC) when the samples were sintered at different temperatures with $p>0.05$, except when samples were sintered at $1500^{\circ} \mathrm{C}$. One-way ANOVA analysis revealed that there was a significant difference in the density of the Ca-SZ from both groups between different sintering temperatures $(p<0.05)$. Further post-hoc Tukey analysis revealed that the density of both materials at $1200{ }^{\circ} \mathrm{C}$ were significantly lower compared to other temperatures with $p<0.05$.

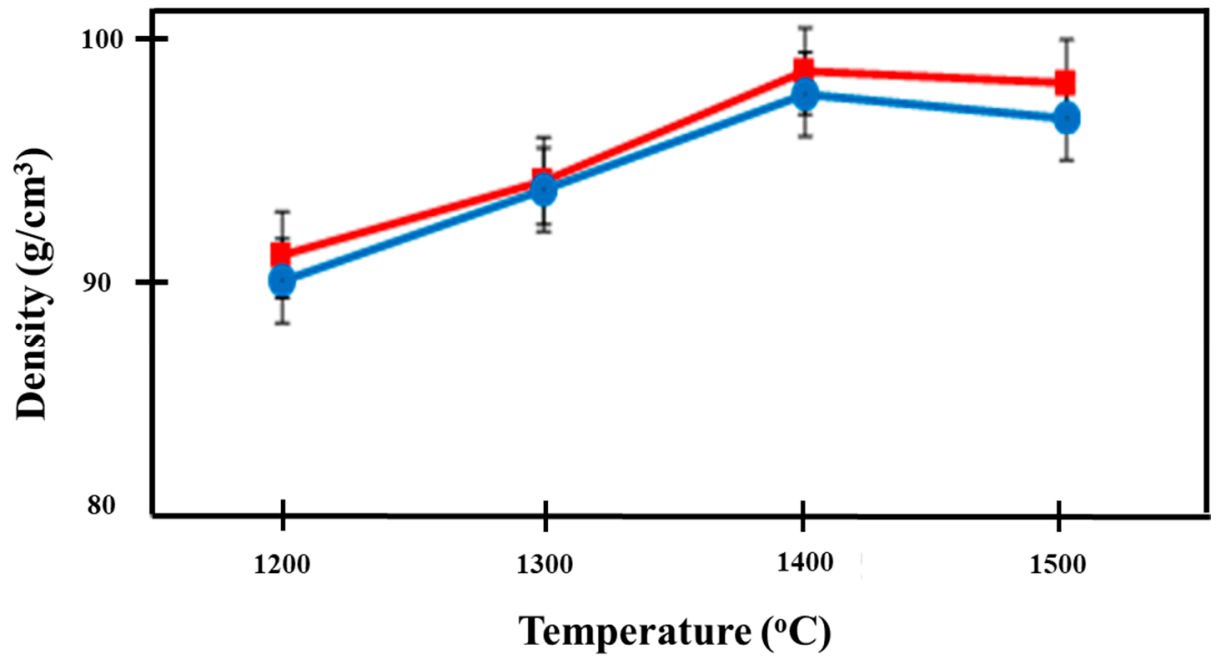

Figure 8. Density of Ca-SZ(CS); red line and Ca-SZ(CC); blue line when sintered for $2 \mathrm{~h}$ at different temperatures of $1200,1300,1400$ and $1500{ }^{\circ} \mathrm{C}$. 


\subsection{Flexural Strength}

Figure 9 shows the increasing trend of flexural strength in both materials with increasing temperature. The independent $t$-test showed no significant difference in the flexural strengths between both groups of Ca-SZ when sintered at different temperatures with $p<0.05$, apart from when the samples were sintered at $1300{ }^{\circ} \mathrm{C}$. The highest flexural strength was observed in Ca-SZ sintered at $1400^{\circ} \mathrm{C}$ for Ca-SZ(CS) and Ca-SZ(CC), with the values of 1165 and $1152 \mathrm{MPa}$, respectively. One-way ANOVA analysis revealed that there was a significant difference in the flexural strength of Ca-SZ(CS) and Ca-SZ(CC) between different sintering temperatures with $p<0.05$. Further post-hoc Tukey test revealed that the flexural strength value of Ca-SZ sintered at $120{ }^{\circ} \mathrm{C}$ was significantly lower compared to other temperatures with $p<0.05$.

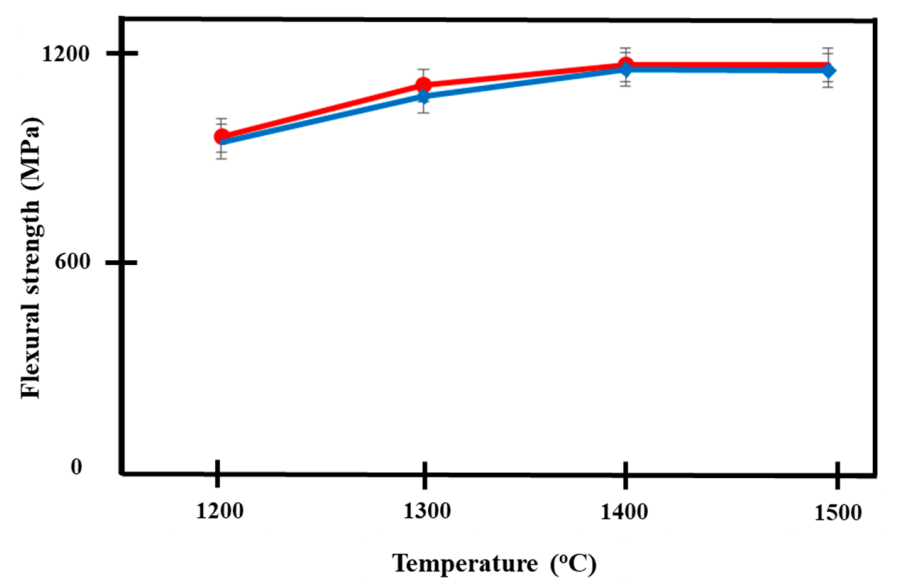

Figure 9. Flexural strength of Ca-SZ(CS); red line and Ca-SZ(CC); blue line when sintered for $2 \mathrm{~h}$ at different temperatures of $1200,1300,1400$ and $1500{ }^{\circ} \mathrm{C}$.

\subsection{Compressive Strength}

Figure 10 shows the increase in compressive strength of both groups of Ca-SZ, as the sintering temperature increases. One-way ANOVA analysis revealed that there was a significant difference in the compressive strength of Ca-SZ(CS) and Ca-SZ(CC) between different sintering temperatures $(p<0.05)$. Further post-hoc Tukey test revealed that the compressive strength of both Ca-SZ groups sintered at temperature $1200{ }^{\circ} \mathrm{C}$ was significantly lower compared to other temperature with $p<0.05$. The independent $t$-test showed that there were no significant differences in the compressive strength of $\mathrm{Ca}-\mathrm{SZ}(\mathrm{CS})$ and Ca-SZ(CC) sintered at different temperature $p<0.05$, with the exception of $1200^{\circ} \mathrm{C}$.

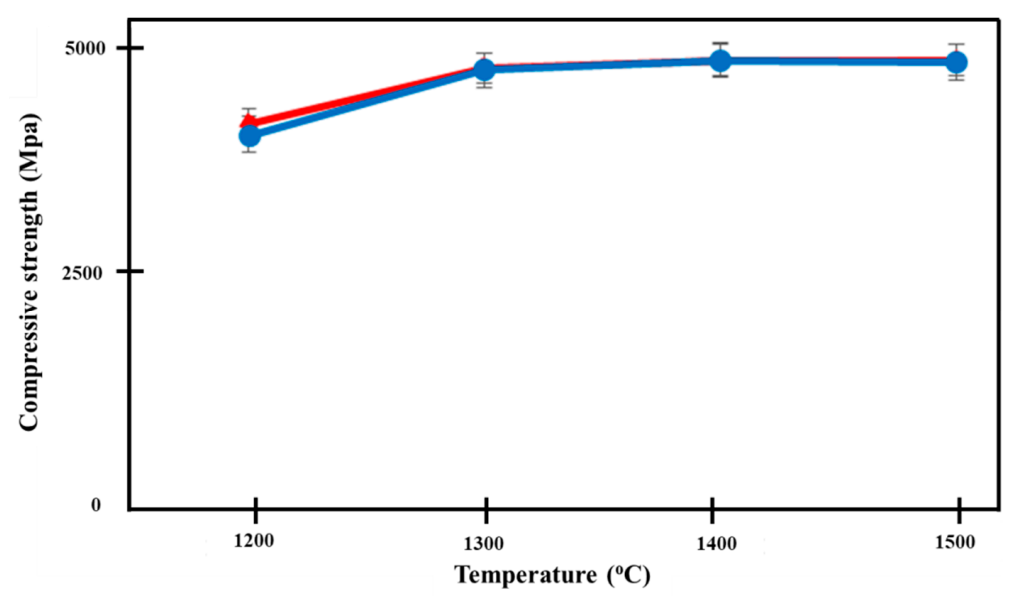

Figure 10. Compressive strength of Ca-SZ(CS); red line and Ca-SZ(CC); blue line when sintered for $2 \mathrm{~h}$ at different temperatures of 1200, 1300, 1400 and $1500{ }^{\circ} \mathrm{C}$. 


\subsection{Vickers Hardness}

Figure 11 illustrates the Vickers hardness values of both Ca-SZ groups. The hardness increased with the increase in sintering temperature, reaching their maximum at $1500{ }^{\circ} \mathrm{C}$ in both Ca-SZ(CS) and Ca-SZ(CC). One-way ANOVA analysis revealed that there was a significant difference in the Vickers hardness values of Ca-SZ(CS) and Ca-SZ(CC) between different sintering temperatures $(p<0.05)$. Further post-hoc Tukey test revealed that the hardness of the samples sintered at $1200{ }^{\circ} \mathrm{C}$ was significantly lower compared to other temperatures $(p<0.05)$. The independent $t$ test revealed there was a significant difference in the Vickers hardness values between Ca-SZ(CS) and Ca-SZ(CC) at all temperatures $(p<0.05)$, except the group that was sintered at $1400{ }^{\circ} \mathrm{C}$.

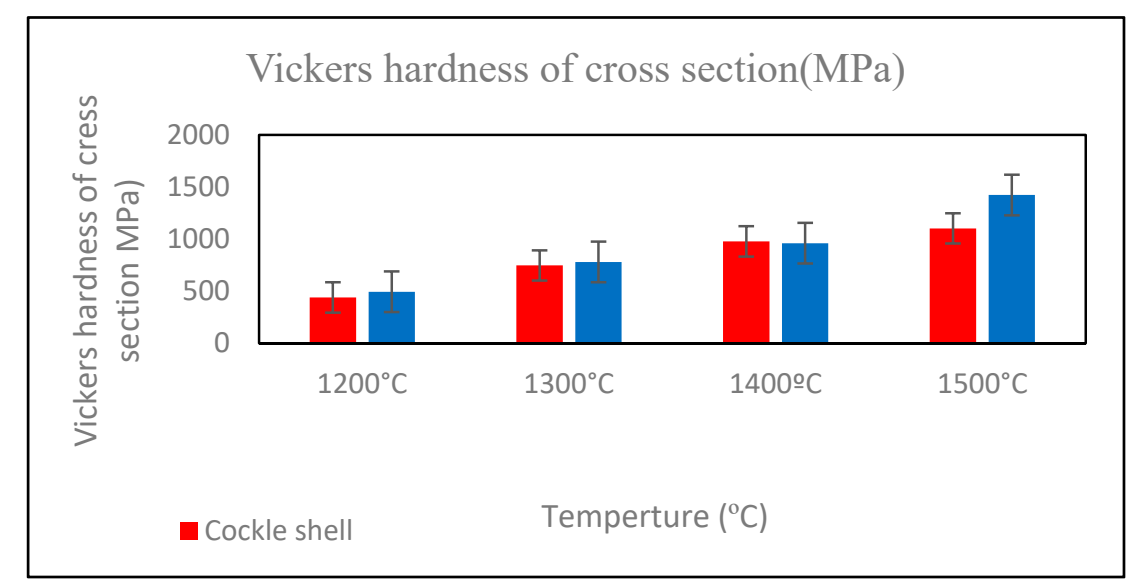

Figure 11. Vickers hardness of cross-section of Ca-SZ(CS); red line and Ca-SZ(CC); blue line when sintered for $2 \mathrm{~h}$ at different temperatures of $1200,1300,1400$ and $1500{ }^{\circ} \mathrm{C}$.

\section{Discussion}

Several studies have worked on stabilizing zirconia with $\mathrm{CaO}$ [19-22] and on obtaining $\mathrm{CaO}$ from cockle shells [23-27]. However, to the authors' knowledge, there has not been any work on the use of $\mathrm{CaO}$ obtained from cockle shells to stabilize zirconia for dental application.

In the current study, XRD analysis showed that the $\mathrm{ZrO}_{2}$ was successfully stabilized with both the nano- $\mathrm{CaO}$ derived from cockle shells and also commercial nano- $\mathrm{CaO}$ (Ca-SZ). Different sintering temperatures $\left(1200^{\circ} \mathrm{C}, 1300^{\circ} \mathrm{C}, 1400^{\circ} \mathrm{C}\right.$, and $\left.1500^{\circ} \mathrm{C}\right)$ were used to prepare Ca-SZ pellets. Physical and mechanical properties of Ca-SZ(CS) were compared with Ca-SZ(CC).

The morphological micrographs of Ca-SZ were characterized by SEM in order to deduce its surface structure and the average particle size. The particle sizes of Ca-PSZ(CS) and Ca-SZ(CC) obtained in the current study were $267 \mathrm{~nm}$ and $272 \mathrm{~nm}$, respectively. The particle size of $\mathrm{CaO}$ derived from cockle shells ranged from 22 to $70 \mathrm{~nm}$ [17] and the particle size of the commercial $\mathrm{CaO}$ was $<160 \mathrm{~nm}$ as compared to the $0.6-\mu \mathrm{m}$ grain size of yttria used in a previous study [28]. The smaller particle size of the $\mathrm{CaO}$ derived from cockle shells might provide a larger surface area for $\mathrm{CaO}$ to be uniformly dispersed on the surface of $\mathrm{ZrO}_{2}$ and therefore may enhance the mechanical properties of the material [29], hence making the material more resistant to degradation or transformation [28]. The application of external heat during sintering enables the Ca-PSZ particle to be closely packed, with pores or voids removed, leading to shrinkage of the materials and forming more compact structures [18]. The voids and spaces shown on the polished surface of both Ca-PSZ pellets when sintered at lower temperatures suggests insufficient heat energy supplied in order to densely pack the materials, leading to an irregular surface upon polishing. Ca-PSZ(CS) sintered at $1400{ }^{\circ} \mathrm{C}$ showed the glossiest appearance with minimum surface crack, in addition to the smooth texture, which is indicative of sufficient and optimum heat energy during the sintering of the material. 
The density of the materials is inter-correlated with the porosity of the microstructure. The incorporation of the $\mathrm{Ca}$ particle in $\mathrm{ZrO}_{2}$ solid solution was probably the main reason the density of the prepared material increased for both groups. The increase in density of the prepared materials as the sintering temperature increased was in agreement with other researchers $[18,30,31]$. The slight enhancement of the density of Ca-SZ(CS) was in accordance with the SEM image in Figure 6, showing a compact structure with smooth morphology. However, the decrement of the density of Ca-PSZ for both specimens over $1400{ }^{\circ} \mathrm{C}$ was probably due to surface diffusion phenomenon as previously reported [32,33].

The highest flexural strength was observed in Ca-SZ(CS) and Ca-SZ(CC) sintered at $1400{ }^{\circ} \mathrm{C}$ with the values of 1165 and $1152 \mathrm{MPa}$, respectively. These values were higher than another study, which reported the flexural strength value of 800-1000 MPa [3]. The higher flexural strength of the $\mathrm{Ca}-\mathrm{SZ}$ in the present study was in accord with Stawarczyk et al. who reported that the optimal sintering temperature for the third generation of $\mathrm{ZrO}_{2}$ is in between $1400^{\circ} \mathrm{C}$ and $1550^{\circ} \mathrm{C}$ [34]. Therefore, the high flexural strength of $\mathrm{Ca}-\mathrm{SZ}$ enables the material to afford restorations with less susceptibility to fracture, thus may be suitable for dental application.

The highest compressive strength was achieved when the Ca-SZ was sintered at $1400{ }^{\circ} \mathrm{C}$, with similar values of 4914 and $4913 \mathrm{MPa}$ for Ca-PSZ(CS) and Ca-SZ(CC), respectively. The current result is in agreement with a previous report by $\mathrm{Hu}$ et al. [35]. The shrinkage and distance of the particles depend on the strength of the cohesion between the particles of the material, as well as the shape and size of the particles. The more particles form close to a spherical shape, the more likely they are to bind the particles together leading to high compressive strength [35]. The higher compressive strength in the current study was probably due to more particles forming close to their spherical shape, which further enhanced the bonding, in addition to the densification of the material.

The mean Vickers hardness of Ca-SZ(CS) and Ca-SZ(CC) was $977 \mathrm{MPa}$ and $960 \mathrm{MPa}$, respectively, which are lower in comparison to the Vickers hardness of Ce-TZP, which was around $1200 \mathrm{MPa}$ [35,36]. Turon-Vinas et al. [29] developed pure $10 \mathrm{~mol} \%$ ceria-stabilized tetragonal zirconia polycrystal (10Ce-TZP) with hardness value of $6.2 \mathrm{GPa}$. Tavor-Vargas et al. reinforced ceria-calcia stabilized zirconia with alumina, and reported hardness of $10 \mathrm{GPa}-13 \mathrm{GPa}$ [22]. Thus, it can be seen in the current study that the zirconia stabilized with calcia produced lower Vickers hardness when compared to the zirconia stabilized using other oxides, which suggests that it is easier to prepare using cutting tools with minimal wear.

In general, all mechanical properties show optimum values when the specimens were sintered at $1400{ }^{\circ} \mathrm{C}$. At $1200{ }^{\circ} \mathrm{C}$, the heat was not sufficient to fully sinter the zirconia and the presence of pores and voids lead to its lower density, flexural, compressive and hardness values. Whereas, at $1500{ }^{\circ} \mathrm{C}$, the zirconia was overheated, showing lower mechanical properties.

Other properties that are important to dental zirconia should be tested in future research. These results are limited to in-vitro study. Further in-vivo animal studies are needed to test tissue response to the current material, followed by clinical trials. Currently the material is produced in a small quantity. More work is needed for upscaling to prepare for possibility of future commercialization.

\section{Conclusions}

The zirconia was successfully stabilized with nano-CaO derived from cockle shells and from commercial source into tetragonal and cubic phase (Ca-SZ) using a physical mixing technique. The physical and mechanical properties of the material were at their optimum when the pellets were sintered at $1400{ }^{\circ} \mathrm{C}$. The physical and mechanical properties of the fabricated Ca-SZ with nano-CaO derived from cockle shell were comparable to the $\mathrm{Ca}-\mathrm{SZ}$ stabilized by commercial nano-CaO. The flexural, compressive strength are also comparable with zirconia stabilized by other oxides, namely, Y-TZP. The fully sintered Ca-SZ is less hard compared to Ce-TZP, which makes it easier to mill. From the study, it can be concluded that the experimental Ca-PSZ with the CaO derived from cockle shells may be used as an alternative to the current zirconia available on the market for dental application. 
Author Contributions: Conceptualization, Z.A.-G., I.A.R., A.H.; methodology, A.I.H., A.N.C.M., N.A.A.A.W.; data analysis, A.I.H.; investigation, A.I.H., A.N.C.M.; resources, Z.A.-G., I.A.R.; writing—original draft preparation, A.I.H., A.N.C.M.; writing-review and editing, Z.A.-G., I.A.R., A.N.C.M.; supervision, Z.A.-G., I.A.R., A.H.; project administration, Z.A.-G.; funding acquisition, Z.A.-G., I.A.R., A.H. All authors have read and agreed to the published version of the manuscript.

Funding: This research was funded by Science Fund from the Ministry of Science, Technology and Innovation (MOSTI) with the grant number: 07-01-05 SF0845 (305/PPSG/6113701).

Acknowledgments: The authors would also like to acknowledge all Multidisciplinary Laboratory (MDL) staff for their support in providing kind assistance.

Conflicts of Interest: The authors declare no conflict of interest. The funders had no role in the design of the study; in the collection, analyses, or interpretation of data; in the writing of the manuscript, or in the decision to publish the results.

\section{References}

1. Afrashtehfar, K.I.; Del Fabbro, M. Clinical performance of zirconia implants: A meta-review. J. Prosthet. Dent. 2020, 123, 419-426. [CrossRef] [PubMed]

2. Raigrodski, A.J. Contemporary materials and technologies for all-ceramic fixed partial dentures: A review of the literature. J. Prosthet. Dent. 2004, 92, 557-562. [CrossRef] [PubMed]

3. Denry, I.; Kelly, J.R. State of the art of zirconia for dental applications. Dent. Mater. 2008, 24, $299-307$. [CrossRef] [PubMed]

4. Lazar, D.R.; Bottino, M.C.; Özcan, M.; Valandro, L.F.; Amaral, R.; Ussui, V.; Bressiani, A.H. Y-TZP ceramic processing from coprecipitated powders: A comparative study with three commercial dental ceramics. Dent. Mater. 2008, 24, 1676-1685. [CrossRef]

5. Piconi, C.; Maccauro, G. Zirconia as a ceramic biomaterial. Biomaterials 1999, 20, 1-25. [CrossRef]

6. Dion, I.; Rouais, F.; Baquey, C.; Lahaye, M.; Salmon, R.; Trut, L.; Cazorla, J.; Huong, P.; Monties, J.; Havlik, P. Physico-chemistry and cytotoxicity of ceramics: Part I-Characterization of ceramic powders. J. Mater. Sci. Mater. Med. 1997, 8, 325-332. [CrossRef]

7. Nawa, M.; Nakamoto, S.; Sekino, T.; Niihara, K. Tough and strong Ce-TZP/alumina nanocomposites doped with titania. Ceram. Int. 1998, 24, 497-506. [CrossRef]

8. Tanaka, K.; Tamura, J.; Kawanabe, K.; Nawa, M.; Oka, M.; Uchida, M.; Kokubo, T.; Nakamura, T. Ce-TZP/Al $2 \mathrm{O}_{3}$ nanocomposite as a bearing material in total joint replacement. J. Biomed. Mater. Res. 2002, 63, 262-270. [CrossRef]

9. Christel, P.; Meunier, A.; Heller, M.; Torre, J.; Peille, C. Mechanical properties and short-term in vivo evaluation of yttrium-oxide-partially-stabilized zirconia. J. Biomed. Mater. Res. 1989, 23, 45-61. [CrossRef]

10. Guazzato, M.; Albakry, M.; Ringer, S.P.; Swain, M.V. Strength, fracture toughness and microstructure of a selection of all-ceramic materials. Part II. Zirconia-based dental ceramics. Dent. Mater. 2004, 20, 449-456. [CrossRef]

11. Strub, J.R.; Rekow, E.D.; Witkowski, S. Computer-aided design and fabrication of dental restorations: Current systems and future possibilities. J. Am. Dent. Assoc. 2006, 137, 1289-1296. [CrossRef] [PubMed]

12. Miyazaki, T.; Nakamura, T.; Matsumura, H.; Ban, S.; Kobayashi, T. Current status of zirconia restoration. J. Prosthodont. Res. 2013, 57, 236-261. [CrossRef] [PubMed]

13. Hannink, R.H.; Kelly, P.M.; Muddle, B.C. Transformation toughening in zirconia-containing ceramics. J. Am. Ceram. Soc. 2000, 83, 461-487. [CrossRef]

14. Kohorst, P.; Borchers, L.; Strempel, J.; Stiesch, M.; Hassel, T.; Bach, F.-W.; Hübsch, C. Low-temperature degradation of different zirconia ceramics for dental applications. Acta Biomater. 2012, 8, 1213-1220. [CrossRef] [PubMed]

15. Nath, S.; Sinha, N.; Basu, B. Microstructure, mechanical and tribological properties of microwave sintered calcia-doped zirconia for biomedical applications. Ceram. Int. 2008, 34, 1509-1520. [CrossRef]

16. Drazin, J.W.; Castro, R.H. Phase stability in calcia-doped zirconia nanocrystals. J. Am. Ceram. Soc. 2016, 99, 1778-1785. [CrossRef]

17. Hussein, A.I. Synthesis of Nano Calcium Oxide from Cockle Shells as Stabilizer for Fabrication of Zirconia. Ph.D. Thesis, Pusat Pengajian Sains Pergigian, Universiti Sains Malaysia, Penang, Malaysia, 2018. 
18. Wahi, A.; Muhamad, N.; Sulong, A.B.; Ahmad, R.N. Effect of sintering temperature on density, hardness and strength of $\mathrm{MIM} \mathrm{Co}_{30} \mathrm{Cr}_{6} \mathrm{Mo}$ biomedical alloy. J. Jpn. Soc. Powder Powder Metall. 2016, 63, 434-437. [CrossRef]

19. Radfarnia, H.R.; Iliuta, M.C. Development of zirconium-stabilized calcium oxide absorbent for cyclic high-temperature $\mathrm{CO}_{2}$ capture. Ind. Eng. Chem. Res. 2012, 51, 10390-10398. [CrossRef]

20. Gempita, G.; Hasratiningsih, Z.; Subrata, G.; Purwasasmita, B.S. Synthesis of mesh-shaped calcia partially stabilized zirconia using eggshell membrane template as filler composite. Padjadjaran J. Dent. 2017, 29. [CrossRef]

21. Kurapova, O.Y.; Glumov, O.; Pivovarov, M.; Golubev, S.; Konakov, V. Structure and conductivity of calcia stabilized zirconia ceramics, manufactured from freeze-dried nanopowder. Rev. Adv. Mater. Sci. 2017, 52, 134-141.

22. Tovar-Vargas, D.; Turon-Vinas, M.; Anglada, M.; Jimenez-Pique, E. Enhancement of mechanical properties of ceria-calcia stabilized zirconia by alumina reinforcement. J. Eur. Ceram. Soc. 2020. [CrossRef]

23. Jung, J.-H.; Yon, S.-J.; Seok, J.-W. Cubic zirconia single crystal growth using shell by skull melting method. J. Korean Cryst. Growth Cryst. Technol. 2013, 23, 124-128. [CrossRef]

24. Buasri, A.; Chaiyut, N.; Loryuenyong, V.; Worawanitchaphong, P.; Trongyong, S. Calcium oxide derived from waste shells of mussel, cockle, and scallop as the heterogeneous catalyst for biodiesel production. Sci. World J. 2013, 2013. [CrossRef] [PubMed]

25. Laonapakul, T.; Sutthi, R.; Chaikool, P.; Mutoh, Y.; Chindaprasirt, P. Optimum conditions for preparation of bio-calcium from blood cockle and golden apple snail shells and characterization. Sci. Asia 2019, 45, 10-20. [CrossRef]

26. Ghazali, S.S.; Kem, K.L.; Jusoh, R.; Abdullah, S.; Shariffuddin, J.H. Evaluation of La-Doped CaO Derived from Cockle Shells for Photodegradation of POME. Bull. Chem. React. Eng. Catal. 2019, 14, 205. [CrossRef]

27. Mohamad, S.F.S.; Mohamad, S.; Jemaat, Z. Study of calcination condition on decomposition of calcium carbonate in waste cockle shell to calcium oxide using thermal gravimetric analysis. ARPN J. Eng. Appl. Sci. 2016, 11, 9917-9921.

28. Papanagiotou, H.P.; Morgano, S.M.; Giordano, R.A.; Pober, R. In vitro evaluation of low-temperature aging effects and finishing procedures on the flexural strength and structural stability of Y-TZP dental ceramics. J. Prosthet. Dent. 2006, 96, 154-164. [CrossRef]

29. Turon-Vinas, M.; Zhang, F.; Vleugels, J.; Anglada, M. Effect of calcia co-doping on ceria-stabilized zirconia. J. Eur. Ceram. Soc. 2018, 38, 2621-2631. [CrossRef]

30. Jaiswal, N.; Kumar, D.; Upadhyay, S.; Parkash, O. Ceria co-doped with calcium (Ca) and strontium (Sr): A potential candidate as a solid electrolyte for intermediate temperature solid oxide fuel cells. Ionics 2014, 20, 45-54. [CrossRef]

31. Jaiswal, N.; Kumar, D.; Upadhyay, S.; Parkash, O. Effect of Mg and Sr co-doping on the electrical properties of ceria-based electrolyte materials for intermediate temperature solid oxide fuel cells. J. Alloys Compd. 2013, 577, 456-462. [CrossRef]

32. Meng, F.; Liu, C.; Zhang, F.; Tian, Z.; Huang, W. Densification and mechanical properties of fine-grained $\mathrm{Al}_{2} \mathrm{O}_{3}-\mathrm{ZrO}_{2}$ composites consolidated by spark plasma sintering. J. Alloys Compd. 2012, 512, 63-67. [CrossRef]

33. Wang, C.-J.; Huang, C.-Y.; Wu, Y.-C. Two-step sintering of fine alumina-zirconia ceramics. Ceram. Int. 2009, 35, 1467-1472. [CrossRef]

34. Stawarczyk, B.; Özcan, M.; Hallmann, L.; Ender, A.; Mehl, A.; Hämmerlet, C.H. The effect of zirconia sintering temperature on flexural strength, grain size, and contrast ratio. Clin. Oral Investig. 2013, 17, $269-274$. [CrossRef] [PubMed]

35. Hu, L.; Wang, C.-A. Effect of sintering temperature on compressive strength of porous yttria-stabilized zirconia ceramics. Ceram. Int. 2010, 36, 1697-1701. [CrossRef]

36. Benzaid, R.; Chevalier, J.; Saâdaoui, M.; Fantozzi, G.; Nawa, M.; Diaz, L.A.; Torrecillas, R. Fracture toughness, strength and slow crack growth in a ceria stabilized zirconia-alumina nanocomposite for medical applications. Biomaterials 2008, 29, 3636-3641. [CrossRef]

(C) 2020 by the authors. Licensee MDPI, Basel, Switzerland. This article is an open access article distributed under the terms and conditions of the Creative Commons Attribution (CC BY) license (http://creativecommons.org/licenses/by/4.0/). 